\title{
An experimental comparison between rival theories of rapid automatized naming performance and its relationship to reading
}

Article

Accepted Version

Powell, D., Stainthorp, R., Stuart, M., Garwood, H. and Quinlan, P. (2007) An experimental comparison between rival theories of rapid automatized naming performance and its relationship to reading. Journal of Experimental Child Psychology, 98 (1). pp. 46-68. ISSN 0022-0965 doi: https://doi.org/10.1016/j.jecp.2007.04.003 Available at https://centaur.reading.ac.uk/36269/

It is advisable to refer to the publisher's version if you intend to cite from the work. See Guidance on citing.

Published version at: http://www.sciencedirect.com/science/article/pii/S0022096507000550

To link to this article DOI: http://dx.doi.org/10.1016/j.jecp.2007.04.003

Publisher: Elsevier

All outputs in CentAUR are protected by Intellectual Property Rights law, including copyright law. Copyright and IPR is retained by the creators or other copyright holders. Terms and conditions for use of this material are defined in the End User Agreement. 


\section{www.reading.ac.uk/centaur}

\section{CentAUR}

Central Archive at the University of Reading

Reading's research outputs online 
An experimental comparison between rival theories of Rapid Automatized Naming (RAN) performance and its relationship to reading

$$
\begin{gathered}
\text { Daisy Powell }^{1,3} \\
\text { Rhona Stainthorp }^{1,4} \\
\text { Morag Stuart }^{1} \\
\text { Holly Garwood }^{1,5} \\
\text { Philip Quinlan }^{2}
\end{gathered}
$$

\author{
${ }^{1}$ Institute of Education, University of London, $U K$ \\ ${ }^{2}$ Department of Psychology, University of York, UK \\ ${ }^{3}$ Now at Roehampton University, UK \\ ${ }^{4}$ Now at Institute of Education, University of Reading, UK \\ ${ }^{5}$ Now at Birkbeck, University of London, UK
}

Address for correspondence:

Daisy Powell

Psychology Department, School of Human \& Life Sciences

Roehampton University, Whitelands College

Holybourne Avenue, London SW15 4JD

Email: d.powell@ roehampton.ac.uk

Tel: +44 (0)208 392 3757; Fax: +44 (0)208 3923527 


\title{
An experimental comparison between rival theories of Rapid Automatized Naming
}

(RAN) performance and its relationship to reading

\begin{abstract}
Two studies investigated the degree to which the relationship between Rapid Automatized Naming (RAN) performance and reading development is driven by shared phonological processes. Study 1 assessed RAN, phonological awareness and reading performance in 1010 children aged 7-10 years. Results showed that RAN deficits occurred in the absence of phonological awareness deficits. These were accompanied by modest reading delays. In structural equation modeling, solutions where RAN was subsumed within a phonological processing factor did not provide a good fit to the data, suggesting that processes outside phonology may drive RAN performance and its association with reading. Study 2 investigated Kail's (1991) proposal that speed of processing underlies this relationship. Children with single RAN deficits showed slower speed of processing than closely matched controls performing normally on RAN. However, regression analysis revealed that RAN made a unique contribution to reading even after accounting for processing speed. Theoretical implications are discussed.
\end{abstract}

Keywords: reading development; visual word recognition; rapid automatized naming; phonological processes; speed of processing. 


\section{Introduction}

Since the seminal work of Denckla and Rudel in the 1970's (1974, 1976), which established the existence of a significant relationship between children's ability to perform well on Rapid Automatized Naming (RAN) tasks and their reading development, extensive research has been carried out to investigate the nature of this relationship. RAN tasks require children to name arrays of familiar items, either letters, digits, colors or objects, as quickly as they can. While performance on the colors and objects versions of the task is a useful predictor of reading achievement in pre-literate children, the alphanumeric versions have been shown to be most strongly and enduringly related to reading. In fact RAN performance rates alongside phonological awareness as one of the most powerful predictors of reading in the English language, and as the strongest predictor of reading in shallow orthographies (Brizzolara, Chilosi, \& Cipriani, 2006; Wimmer, 1993).

As well as its predictive relationship with reading performance (see Swanson, Trainin, Necoechea \& Hammill, 2003, for a meta-analysis), performance on RAN tasks has also been shown to discriminate between good and poor readers (Ackerman \& Dykman, 1993; Bowers, Steffy, \& Tate, 1998; Denckla \& Rudel, 1976) and can also distinguish children with dyslexia from age-matched, normally developing readers. As a result, several competing theoretical accounts have been developed to attempt to explain the relationship between RAN performance and both normal and atypical development. Consistent with the phonological processing deficit theory of developmental dyslexia (Hulme \& Snowling, 1992, Stanovich \& Siegel, 1994; Snowling, 2002), Wagner, Torgesen and colleagues (e.g., Wagner \& Torgesen, 1987) have proposed that RAN tasks are an index of the speed with which phonological 
information can be accessed from memory and are thus best described as tapping into an aspect of phonological processing. By contrast, Wolf and Bowers (e.g., Bowers \& Wolf, 1993; Wolf \& Bowers, 1999) propose that RAN tasks index processes which are, at least in part, independent of phonology and have put forward a 'double deficit' theory of developmental dyslexia. According to double deficit theory, reading disability can be caused either by phonological processing deficits, RAN deficits, or in the most severe cases, by a combination of both deficits. While the mechanisms driving RAN performance have not yet been fully specified, Wolf and Bowers (1999) have proposed that the cognitive deficits that lead to poor RAN performance impact on reading by interfering with the quality of orthographic representations themselves and with the forming of links between orthographic and phonological representations that are crucial for reading.

A critical issue in discriminating between the two theoretical positions outlined above concerns how separable RAN performance deficits are from phonological processing deficits more generally. Given that RAN performance has generally been shown to correlate with phonological awareness, a pertinent question is whether RAN deficits occur in the absence of phonological deficits. Also critical is the question of whether a single RAN deficit can cause reading problems. Considerable research has investigated these issues, but the evidence so far remains equivocal. In support of double deficit theory, Bowers and Wolf (Bowers, 1995; Bowers \& Wolf, 1993; Wolf \& Bowers, 1999) provided evidence that RAN deficits can occur independently of phonological awareness problems: they identified separate subgroups of reading-disabled children with a single RAN deficit, children with a single phonological awareness deficit, and children with problems in both domains. The children with a double deficit showed, as predicted, the most profound reading problems, but children with a single 
RAN deficit also had some problems with reading: particular problems relating to comprehension and to word, rather than non-word, reading were documented. Badian (1997) has similarly reported that very poor readers typically exhibit deficits when performing both RAN and phonological awareness tasks, as well as a third deficit described as orthographic.

Further evidence of a dissociation between RAN and phonological awareness has been obtained from a number of correlational studies, which have demonstrated that early RAN performance accounts for a significant proportion of the variance in both concurrent and future reading measures, independent of the variance attributable to phonological awareness and measures of IQ (Ackerman \& Dykman, 1993; Badian, 1993; Blachman, 1984; Felton \& Brown, 1990; Manis, Seidenberg, \& Doi, 1999). In children with reading disabilities, the predictive relationship between RAN performance and reading appears to be stronger and to endure longer through development (McBride-Chang \& Manis, 1996; Meyer, Wood, Hart, \& Felton, 1998) than in typically developing children. Meyer et al. (1998) found that, in a sample of reading disabled children, RAN but not phonemic awareness predicted later reading performance, even when the autoregressive effects of prior reading level were accounted for.

However, Wagner, Torgesen, Rashotte, Hecht, Barker, Burgess, Donahue and Garon (1997) reported data that provide a subtly different picture of the inter-relationships between phonological awareness, RAN and reading. They found that RAN scores accounted for unique variance in reading, over and above the contribution of prior reading level and phonological awareness, in the early stages of their longitudinal study. From third grade onwards, however, only phonological awareness made a unique contribution to the children's reading performance, over and above the autoregressive effects of prior reading level. 
Furthermore, Torgesen, Wagner, Rashotte, Burgess, and Hecht (1997) provided additional evidence of the complexity of the relationships between RAN, phonological awareness and reading. This evidence came from a longitudinal study in which the children were slightly older at the onset of the study than in the earlier report. It was found that when the autoregressive effects of reading were included in the analysis, RAN performance did not predict any unique variance in any of the reading measures they used, whereas phonological awareness did.

The equivocal results reported in the studies outlined above highlight the fact that many questions remain surrounding the nature of the relationship between RAN performance and reading. The complex and perhaps time-limited inter-relationships between RAN, phonological awareness and reading itself make causal inferences very difficult: it is not yet known what cognitive processes underlie RAN and account for its relationship with reading. The degree to which individual differences in RAN performance are driven by individual differences in phonological processing more generally is also unclear. One reason for the lack of clarity about the causal nature of the link between RAN and reading is that many of the studies outlined above have been correlational. Thus they cannot rule out the possibility that rather than being causal in nature, the relationship between RAN and reading is driven by a third, unknown factor. This view has been put forward by Kail (Kail, 1991; Kail \& Hall, 1994; Kail, Hall, \& Caskey, 1999), who argued that, rather than being restricted to the reading system or even to linguistic processes, RAN performance reflects more generalized processing speed. According to Kail, childhood is marked by a gradual increase in global processing speed. The relationship between RAN and reading is explained, in Kail's view, by the fact that both are influenced by the same underlying factor, namely, processing speed. 
This view has been supported by evidence (Kail et al., 1999) that the relationship between RAN and reading is driven by age-related changes in processing speed. The relationship between processing speed and reading was also investigated by Cutting and Denckla (2001), who found in a relatively small sample of first to third grade children, that processing speed related indirectly to reading through its influence on both phonological awareness and rapid serial naming.

The aim of the current research is to provide evidence relevant to the different theoretical positions outlined above. As mentioned previously, a critical issue in discriminating between double deficit and phonological core deficit theories of reading disorders surrounds the question of whether the processes that drive RAN performance and underlie its relationship with reading are, as several researchers (Wagner \& Torgesen, 1987; Share, 1995) have proposed, the same phonological processes that underlie reading itself. The alternative view is that RAN performance is driven by processes that are at least in part independent of phonology; a view consistent with double deficit theory. If RAN performance does dissociate from phonology, further questions are therefore raised concerning the cognitive mechanisms that underlie RAN. It is possible that, as proposed by Kail, the locus of RAN deficits is outside the linguistic system, and is best understood as relating to generalized speed of processing deficits.

To address these issues, our first study measured RAN performance, phonological processing, and reading skills in a large sample of British 7-10 year-old children, in order to 1) investigate the degree to which performance on RAN tasks and phonological awareness skills dissociate in these children in a UK sample; and, 2) investigate the incidence of single RAN, single phonological awareness, and double deficits, and the implications of these 
different profiles for the children's reading progress. The underlying structure of the data set was examined using structural equation modeling techniques, to compare solutions in which RAN and phonological awareness were instantiated as separate factors with those where a single factor drove performance on both. These analyses aimed to provide further evidence relevant to the continuing debate between double deficit and phonological core deficit theories of reading disorders.

The focus of our second study was to begin the process of unpacking the cognitive factors that underlie performance on RAN tasks, using experimental, rather than correlational methods. We compared speed of processing in children who exhibit problems performing RAN tasks, in the absence of phonological awareness deficits, with children performing normally on RAN. Children in both groups were matched carefully on measures of verbal and non-verbal abilities and, crucially, on phonological awareness, in order to circumvent the methodological difficulties associated with the confounding influence of phonological awareness on RAN in relation to reading. Thus, Study 2 was designed to investigate whether the association between low RAN and poor reading is caused by a speed of processing deficit that underlies both RAN performance and reading difficulties. 
Study 1

\section{Method}

\section{$\underline{\text { Participants }}$}

Participants were 1010 children attending 9 different schools in the Kingston upon Thames area of Surrey, UK. At the first time of testing, which took place during the autumn and spring school terms, 499 children were in Year 3 (mean age: 7:8 years; range: 7:2-8:5 years) and 511 in Year 4 (mean age: 8:9 years; range: 8:1-9:7 years) ${ }^{1}$. Of the Year 3 sample, 254 were girls and 245 were boys; in Year 4 there were 256 girls and 255 boys. The majority of these children were monolingual English speakers (447 in Year 3 and 437 in Year 4). Only data from these 884 monolingual children are reported.

\section{$\underline{\text { Materials and Measures }}$}

Phonological awareness, phonological memory and RAN were assessed using the six core subtests of the Comprehensive Test of Phonological Processing (Wagner, Torgesen \& Rashotte, 1999). Two subtests assess phonological awareness: the Elision subtest required words to be spoken after deleting a designated sound (e.g., "Say cup without saying /k/"); the Blending Words subtest involved combining sounds to form words (e.g., "What words do these sounds make? m-ă-d") . A further two subtests assess phonological memory: a digit span task (Memory for Digits) and a nonword repetition task. Finally, two of the core subtests of the Comprehensive Test of Phonological Processing assess RAN in its digit and letter naming forms. Both RAN subtests require participants to name, as quickly as possible,

\footnotetext{
${ }^{1}$ In the UK, children in Year 3 are in their third year of formal literacy instruction. Thus Year 3 in the UK equates to Grade 3 in the US in terms of prior years of literacy instruction, but to Grade 2 in terms of chronological age.
} 
two $4 \times 9$ arrays containing repetitions of 6 letters/digits. Times taken to complete the two arrays are combined to provide a score, in seconds, for each RAN subtest.

Reading ability was assessed using the British Ability Scales single word reading test (Elliot, Murray \& Pearson, 1983). This requires children to read aloud single words of increasing difficulty. Only correct pronunciations of words were accepted, and testing was abandoned if children made more than 10 consecutive errors.

\section{$\underline{\text { Procedure }}$}

Informed parental consent was obtained via letters mailed by each school. Children were tested individually in a quiet area away from the classroom in one session lasting approximately 20 minutes. During this session the children completed the British Ability Scales single word reading test and then the six core subtests of the Comprehensive Test of Phonological Processing (full details of the administration and scoring procedures are given in Wagner et al., 1999).

\section{$\underline{\text { Results }}$}

Table 1 presents the means and standard deviations of the raw and standard scores (Wagner et al., 1999) of the six core subtests of the Comprehensive Test of Phonological Processing, as well as raw scores and indices of reading age for the British Ability Scales single word reading test. Our large sample of typically developing UK children performed in a broadly similar manner to the sample of American children described in Wagner et al., 1999, with mean standard scores within one standard deviation of the mean for all tasks. However, there were key differences: The UK sample performed slightly better on the RAN 
tasks than the US children but rather worse on the blending subtest of phonological awareness and the nonword repetition subtest of phonological memory. Because of the discrepancies between our sample and the published norms, we based all further analyses on raw scores.

Table 1 around here

In order to investigate whether there was a dissociation between RAN and phonological awareness in our sample, we first summed raw scores for the two subtests measuring phonological awareness (elision and blending) and RAN (RAN letters and RAN digits), and then calculated $\mathrm{z}$ scores as composite measures, separately for each year group. For ease of interpretation, we also inverted RAN z scores, so that a high score represented high, not low performance. Figure 1 plots the relationship between RAN and phonological awareness for both Year 3 (left panel) and Year 4 (right panel) children.

Figure 1 around here

As figure 1 shows, the majority of children's performance fell within one standard deviation of the mean for both phonological awareness and RAN, though some children performed poorly on only one measure, and some on both. To investigate further the performance profile of our sample on these tasks we used phonological awareness and $\mathrm{RAN} \mathrm{z}$ scores to place children into one of four subgroups. Children whose phonological awareness and RAN z scores were both above -1 standard deviation of the mean were defined as the "no 
deficit' group. Children whose phonological awareness z scores were less than 1 standard deviation below the mean but whose RAN z scores were more than or equal to -1 standard deviation of the mean were defined as the single phonological awareness deficit group. Children whose RAN z scores were less than 1 standard deviation below the mean but whose phonological awareness $\mathrm{z}$ scores were more than or equal to -1 standard deviation of the mean were defined as the single RAN deficit group. Finally, children with z scores below -1 standard deviation of the mean on both phonological awareness and RAN tasks were defined as the 'double deficit' group.

Twelve children could not be classified according to these criteria, as they made more than 5 errors on one of the RAN tasks and they therefore did not obtain a score for RAN; these children were excluded from further analyses. To investigate the relative impact of a single phonological awareness deficit, a single RAN deficit and a double deficit on reading performance, we calculated the mean British Ability Scales single word reading score for the children falling into each quadrant. These data are shown in Table 2.

Table 2 about here

Data in Table 2 indicate that the double deficit group, both in Year 3 and Year 4, had the most serious reading deficits, performing around 1.5 SDs below the mean on the British Ability Scales single word reading test. Both single phonological awareness and single RAN deficit groups also showed modest reading deficits, with a single phonological awareness deficit appearing to be associated with a somewhat larger deficit than a single RAN deficit in the Year 3 sample (.82 and .49 SDs below the mean, respectively) but not in the Year 4 
sample, where single phonological awareness and RAN deficits resulted in similar levels of reading deficit (.65 and $.62 \mathrm{SDs}$ below the mean, respectively). These findings are broadly consistent with double deficit theory, as was the fact that, in our sample, it was more unusual to have a double than a single deficit. However, this interpretation has been challenged by Schatschneider, Carlson, Francis, Foorman and Fletcher (2002, see also Compton, DeFries, \& Olson, 2001), who highlighted some methodological problems arising from creating subgroups on the basis of the two correlated variables of RAN and phonological awareness. Schatschneider et al. argued that the additional severity of reading problems associated with double as opposed to single deficits arises as a consequence of the fact that children with double deficits tend to be more severely impaired in phonological awareness than children with a single phonological awareness deficit. As Table 2 shows, our data were consistent with Schatschneider et al.'s position, with double deficit groups performing significantly less well on phonological awareness tasks than single phonological awareness deficit groups, both in Year 3 and Year $4\left(\right.$ Year 3: $t_{(74)}=2.293, p<0.05$; Year 4: $\left.t_{(73)}=2.7091, p<0.01\right)$.

The fact remains, however, that RAN deficits occurred in the absence of phonological awareness deficits, which would seem incompatible with theories which view RAN solely as an index of phonological processing. As a consequence we examined this issue further through the use of structural equation modeling techniques. 
Structural Equation Modeling: investigating the factors underlying performance on the six core subtests of the Comprehensive Test of Phonological Processing

\section{$\underline{\text { Structural Equation Modeling Strategy }}$}

We first report the results of a series of analyses using structural equation modeling (Bollen, 1989). The first analysis sought to replicate Wagner, Torgeson and Rashotte's (1999) confirmatory factor analysis, which indicated that a model with three factors (phonological awareness, phonological memory and RAN) provided a good fit to data from the six core subtests of the Comprehensive Test of Phonological Processing test battery. Next we report two further models aimed at investigating whether performance on the Comprehensive Test of Phonological Processing can more parsimoniously be accounted for by models with fewer factors.

We then used structural equation modeling to investigate how the factors underlying performance on the Comprehensive Test of Phonological Processing relate to single word reading scores. We first examined a model with British Ability Scales reading scores predicted by three latent variables: phonological awareness, phonological memory and RAN, and then compared it with a two-factor model (with phonological awareness and phonological memory subsumed into a phonological processing factor and RAN as a second factor) and finally with a single factor model (phonological awareness, phonological memory and RAN all subsumed within a single latent variable).

All structural equation modeling was carried out using AMOS 5.0.1 (Arbuckle, 2003). In order to assess the goodness of fit of the various models we report chi square statistics for each model. Chi square difference tests were used to compare the goodness of fit of the first 3 models we report. However, because the chi square test is known to be sensitive to sample 
size, we also used some additional measures of fit. First, we used two comparative fit indices, the Bentler-Bonett (1980) Normed Fit Index (NFI) and Bollen's Incremental Fit Index (IFI). The NFI and the IFI are both based on a comparison between the model chi square and the independence (or 'null') model, and yield values between 0 and 1 (though as the IFI values, unlike NFI values, are not normed, they may fall either below 0 or above 1), with a value over 0.90 considered as indicative of a good fit. We also report comparative fit index (CFI, Bentler 1988) values, which also involve a comparison between the model and a null model, and returns values from 0 to 1 , with higher values above 0.90 indicating a good fit. Finally, we report values on the root mean square error of approximation (RMSEA), which gives an estimate of the discrepancy in fit per degrees of freedom. RMSEA values vary between 0 and 1 , with values below 0.08 taken as indicating a good fit.

\section{Model 1. Confirmatory factor analysis: three factor solution}

We first sought to replicate Wagner et al.'s (1999) three factor model (phonological awareness, phonological memory and RAN). The results of this analysis are shown in Figure 2, and simple correlations between all manifest variables included in the model are shown in

Table 3. Figure 2 shows that the latent variables of phonological awareness and phonological memory were strongly related to each other, and both were also significantly correlated with RAN. Furthermore, there were strong relationships between the three latent variables and their associated manifest variables: for example, phonological awareness predicted elision and blending. The fit statistics shown in Table 4 also indicate that this model provided an acceptable fit to our data: NFI, IFI and CFI values were all above .95, indicating an excellent fit to the data, with the RMSEA value of 0.077 also indicating a reasonable fit. 
Table 3 around here

Figure 2 around here

\section{Model 2. Confirmatory factor analysis: two factor solution}

We next investigated whether our data could more parsimoniously be accounted for by a model with two latent variables: a phonological processing latent variable, which comprised the four manifest variables that in Model 1 were predicted by phonological awareness (elision and blending) and phonological memory (memory for digits and non-word repetition); and a RAN latent variable. This model is shown in Figure 3 and fit statistics are reported in Table 4.

Figure 3 around here

Figure 3 shows that there was a reasonably strong, significant relationship between the two latent variables, and that each latent variable reliably predicted its associated manifest variables. The NFI, IFI, and CFI statistics indicated an excellent fit to the data, and the RMSEA value was just outside the range conventionally considered acceptable.

Table 4 around here 


\section{Model 3. Confirmatory factor analysis: single factor solution}

Our third confirmatory factor analysis aimed to investigate whether a model with a single factor, collapsing across phonological awareness, phonological memory and RAN, could also provide a reasonable fit to our data. This model, which could perhaps be described as a strong test of theories viewing RAN as an aspect of phonological processing, is shown in Figure 4, and fit indices are reported in Table 4 . Not only did the chi square difference test show that this model provided a significantly worse fit to the data than Model 2, but the other fit measures also indicated a poor fit, with NFI, IF and CFI all less than 0.90, and RMSEA well above an acceptable level.

Figure 4 about here

Model 4. Structural equation model with three latent variables.

Our next step was to investigate how the three factors thought to underlie performance on the Comprehensive Test of Phonological Processing (phonological awareness, phonological memory, and RAN) are predictively related to reading, as assessed by the British Ability Scales single word reading test. The first model we report incorporated 3 factors, represented by the latent variables of phonological awareness, phonological memory and RAN, as in Model 1 above. This model is shown in Figure 5 and fit statistics are reported in Table 5.

Figure 5 about here

The RMSEA value for this model was 0.070 , which in combination with the other fit statistics shown in Table 5 indicated a good fit to our data. Furthermore, the combined $\mathrm{R}^{2}$ 
obtained for the model was 0.74 , indicating a strong predictive relationship between the model's three latent variables and our measure of reading. Phonological awareness was strongly and significantly predictive of reading ( standardized beta $=.83, z=4.659, p<$ 0.001), and there was a weaker, though still significant, independent relationship between RAN and reading (standardized beta $=.184, z=2.992, p<0.01$ ). However, phonological memory, the latent variable associated with the memory for digits and non-word repetition tests, did not predict reading (standardized beta $=.115$ ), $z=.894, p>0.05$ ). This is interesting as it suggests that the moderate correlation between phonological memory and reading was mediated by the other variables of RAN and phonological awareness.

Table 5 about here

\section{Model 5. Structural equation model with two latent variables.}

Model 5, like Model 2, consisted of 2 latent variables: first RAN, and second a composite phonological processing variable associated with all manifest variables originally linked to phonological awareness and phonological memory. Model 5 is shown in Figure 6 and fit statistics are given in Table 5. The combined $\mathrm{R}^{2}$ obtained for the model was .67 , indicating that the two latent variables accounted for a substantial proportion of the variance in reading scores. The latent variable of phonological processing significantly predicted reading scores (standardized beta $=.68, z=12.15, p<0.001$ ), as did RAN (standardized beta $=.23, z=5.995, p<0.001)$. The NFI, IFI, and CFI statistics indicated a good fit to the data, and the RMSEA value was just outside the range conventionally considered acceptable. Taken together, these results suggest that a two-factor model, with performance on phonological awareness and phonological memory tasks seen as driven by common processes but separate processes driving RAN performance, may arguably provide a more parsimonious 
account of the data, though a chi square difference test, reported in Table 5, suggested that this model provided a significantly worse fit to the data than model 4 .

Figure 6 about here

Model 6. Structural equation model with single latent variable.

The final model we report examined the predictive relationships between reading and the 6 tasks comprising the Comprehensive Test of Phonological Processing, when all tasks originally associated with phonological awareness, phonological memory and RAN were putatively driven by a single, phonological processing factor, as was the case in Model 3. Model 6 is graphically represented in Figure 7 and fit statistics are reported in Table 5. The combined $\mathrm{R}^{2}$ for the model was .41 and indeed the single phonological processing factor significantly predicted reading (standardized beta $=.64, z=11.515, p<0.001$ ). However, as Table 5 shows, this model did not provide a good fit to the data: all fit statistics obtained were well outside the acceptable range, and furthermore, a chi square difference test indicated that this model provided a significantly worse fit to the data than model 5.

\section{$\underline{\text { Discussion }}$}

To summarize, our behavioral data provide evidence of a dissociation between RAN and phonological processing in a large sample of typically developing British school children. These data are broadly consistent with the double deficit account of dyslexia: the children in the double deficit group were the poorest readers in our sample, and a sizeable group of children exhibited RAN deficits in the absence of phonological awareness deficits, and vice versa. Despite the fact that, as previously reported by Schatschneider et al., children 
in the double deficit group showed significantly greater deficits in phonological awareness than children in the single phonological awareness deficit group, which might be interpreted as undermining the necessity of postulating a double deficit, the existence of a group of children with a single RAN deficit which was associated with modest impairment in reading is not consistent with the proposal that RAN is simply an index of phonological processing.

We then examined our data using structural equation modeling techniques.

Confirmatory factor analyses suggested that processes underlying RAN are at least partially independent of those underlying phonological processing more generally: a model in which manifest variables assessing RAN, phonological awareness and phonological memory all loaded on the same latent variable did not provide an adequate account of our data, whereas models where RAN was treated as a separate latent variable did. Model 3 could perhaps be interpreted as providing a strong test of the notion that performance on RAN tasks is driven by a common underlying factor to that driving performance on phonological awareness and phonological memory tasks. Our data would then provide evidence against this notion: while the inter-correlations between the RAN, phonological awareness and phonological memory latent variables suggest some common underlying processes, models 1 and 2, which allowed RAN to be independent of phonological processing, provided a more convincing fit to the data. Further support for this position was obtained from the structural equation models reported above, where the degree to which reading performance was predicted by the six core subtasks of the Comprehensive Test of Phonological Processing was examined, and the goodness of fit of models with one, two and three latent variables (models 6, 5 and 4, respectively) was compared. Results suggested that the most appropriate account of the data 
was obtained when RAN and Phonological processing were instantiated as separate underlying latent variables.

Having established that in our sample it appeared that the processes underlying RAN performance were at least partly separable from phonological processing, our next aim was to establish whether, as suggested by Kail et al. (1999), speed of processing deficits underlie performance on RAN tasks.

Study 2

\section{$\underline{\text { Method }}$}

\section{$\underline{\text { Participants }}$}

160 children were selected from the sample described above to form two experimental groups: a Low RAN group and a group of matched controls. The 80 children, 37 in Year 3, 43 in Year 4, comprising the Low RAN group were those children who were identified through the screening procedure described above as having a Single RAN deficit (RAN performance at least one standard deviation below the mean; phonological awareness not less than one standard deviation below the mean).

The remaining 80 children, 37 in Year 3 and 43 in Year 4, formed a control group, and were selected from the No Deficit Group described above (both RAN and phonological awareness scores not less than one standard deviation below the mean). These children were selected on the basis of providing as close as possible a match to children in the Low RAN Group on the following measures: phonological awareness (elision and blending subtests of the Comprehensive Test of Phonological Processing), phonological memory (memory for 
digits and non-word repetition subtests of the Comprehensive Test of Phonological Processing), age, and verbal and non-verbal ability (the vocabulary and block design subtests of the WISC-IIIR (Wechsler, 1992). The characteristics of each sample are summarized in Table 6.

Table 6 about here

$\underline{\text { Materials and Measures }}$

\section{Speed of Processing}

The Cross Out subtest of the Woodcock-Johnson Tests of Cognitive Ability

(Woodcock \& Johnson, 1989) is a pencil and paper, timed measure of speed of processing. The test consists of 30 rows, each comprised of 19 geometrical shapes. On each trial, the task is to scan a row of geometrical figures to find and cross out the five figures identical to a target figure shown on the far left of the row. Full details of the administration and scoring of this task are given in Woodcock and Johnson (1989).

2. Simple and choice reaction time

Computerized tests of simple and choice reaction time were created using E-prime experiment software (Schneider, Eschman \& Zuccolotto, 2002) running on a Dell Latitude D800 laptop with an Intel Pentium processor (1400MHz) and a 13" color screen. The simple reaction time task measured the time taken to make a key-press response following the appearance of a target stimulus on the screen, while the choice reaction time task required participants to decide which of two target stimuli appeared, and make an appropriate key- 
press response as quickly as possible. Six different color drawings of monsters, measuring around $3 \mathrm{X} 3 \mathrm{~cm}$ in size, were the target stimuli in the simple reaction time task, and a further two drawings of monsters were used in the choice reaction time task.

\section{$\underline{\text { Procedure }}$}

There were two test sessions. The first took place during the first half of the summer term, and involved the administration of the Cross Out subtest of the Woodcock Johnson Test of Cognitive Ability (Woodcock \& Johnson, 1989), as a measure of speed of processing. The second session occurred during the second half of the summer term, and involved the administration of computerized choice and simple reaction time tasks. The order in which the participants completed the two reaction time tasks was counterbalanced.

\section{Cross Out task (Woodcock \& Johnson, 1989)}

The children's task was to complete as many of the total 30 trials as possible within a three-minute time limit. Raw scores of total number of items correct within the 3-minute period were recorded for each child.

\section{$\underline{\text { Simple Reaction Time }}$}

In the simple reaction time experiment, each participant saw a welcome screen displaying the six pictures of monsters that acted as target stimuli and the following instructions, "Hello. When you see one of these monsters, press the spacebar as quick as you can". After reading the instructions aloud and ensuring that the child understood the task, the experimenter initiated a block of six practice trials, followed by two blocks of experimental trials. For both practice and experimental blocks, each trial began with the presentation of a black fixation cross in the center of a white screen for $500 \mathrm{~ms}$, followed by a lag, followed by 
the appearance of the target stimulus. The duration of the lag was varied to prevent the children anticipating the moment when the stimulus appeared on the screen and was either 300, 600 or $900 \mathrm{~ms}$. Each lag duration occurred equally often and in random order, as did each of the six target stimuli. The target remained in the center of the screen until the participant made a spacebar response which initiated the next trial. There was a short break of approximately $1000 \mathrm{~ms}$ between blocks. There were 18 trials in each of the two experimental blocks.

\section{Choice Reaction Time}

For the choice reaction time task, the 2 remaining monster stimuli were used. Each participant saw an opening screen displaying the following, "Hello, if you see... [picture of orange monster positioned centrally on the left hand side of the screen] press the orange button or [picture of blue monster centrally positioned on the right side of the screen] press the blue button, as quick as you can”. A small orange sticker was placed on the 'a' key and a blue sticker on the ' 1 ' key. A mouse press initiated the practice block of 12 trials with half the trials containing the orange monster and half the blue. Participants saw a black fixation cross for $500 \mathrm{~ms}$, followed by a lag of 300,600 , or $900 \mathrm{~ms}$ before the target stimulus appeared in the center of the screen. The target stimuli and lag times were randomly selected. The target stimulus remained on the screen until the participant pressed either the ' $a$ ' or the 'l' key. Feedback was given after every practice trial: following a correct response, participants saw a thumbs up sign and the text "That's right, well done!"; following an incorrect response, a screen with the message, “Oops! Try again!” appeared. There were two experimental blocks, each consisting of 18 trials. The procedure for the experimental blocks was exactly the same as for the practice block, with the exception that there was no feedback. 


\section{$\underline{\text { Results and Discussion }}$}

Scores for the Speed of Processing cross-out task are summarized in Table 7. Data were subjected to a two-way ANOVA, with Group (Low RAN and Controls) and Year (Year

3 and Year 4) as between group factors, and number correct, out of a total 30, as the dependent variable. Analysis showed that there was a significant effect of Group, with Low RAN children performing less well than the controls $(F(1,156)=4.263, M S E=9.704, p<$ 0.05). The effect of Year was also significant $(F(1,156)=14.317, M S E=9.704, p<0.001)$, with Year 4 achieving higher scores than Year 3 children. The interaction between Group and Year was not significant $(F(1,156)=<1)$.

Table 7 about here

Raw scores for the simple reaction time task are also given in Table 7. A two-way ANOVA was carried out, with Group and Year as between-group factors, and mean RT as the dependent variable, though data were first subjected to logarithmic transformation to correct a positive skew. Analysis revealed that the low RAN group were significantly slower than the controls $(F(1,155)=4.263, M S E=0.006, p<0.05)$. There was also a significant main effect of Year $(F(1,155)=6.545, M S E=0.006, p<0.05)$. The interaction between Group and Year was not significant $(F(1,156)<1)$.

Data for the choice reaction time task, summarized in Table 7, were subjected to a two-way ANOVA with Group and Year as between-group factors, and mean RT (again logtransformed to correct a positive skew) as the dependent variable. Results showed that in the choice reaction time task the main effect of Group was not significant $(F(1,155)=3.364$, $M S E=0.005, p>0.05)$, though there was a significant main effect of Year $(F(1,155)=$ 
5.534, MSE $=0.005, p<0.05)$. The interaction between Year and Group also failed to reach significance $(F(1,155)=2.975, M S E=9.704, p>0.05)$. These data suggest that the choice component of this task provided no specific difficulty to the Low RAN group.

Table 8 about here

Having established that the Low RAN children were slower than controls on both the speed of processing and the simple reaction time task, we analyzed the data further to investigate the degree to which these speed variables could account for the relationship between RAN and reading. Correlations between the relevant variables are given in Table 8 . Simple reaction time scores were significantly related to RAN performance, but not to reading. However, speed of processing scores and choice reaction time were related both to RAN performance and to reading, presumably reflecting the additional cognitive components involved in performing these tasks, over and above simple reaction time. Hierarchical regression was used to investigate the degree to which speed of processing, simple reaction time and RAN accounted for unique variance in reading scores. With all variables entered in the equation, the regression was significant $(\mathrm{R}=.505, \mathrm{~F}(3,155)=17.71, p<0.001)$. Results showed that simple reaction time was not a significant predictor of reading, even when entered first into the equation $(\mathrm{R}=.136, \mathrm{~F}(1,157)=2.955$, ns $)$. However, when entered second, speed of processing did predict a small but significant proportion of the variance in reading scores $\left(\mathrm{R}_{\text {change }}^{2}=.071, \mathrm{~F}_{\text {change }}(1,156)=12.213, p<0.01\right)$. Importantly, $\mathrm{RAN}$ accounted for around $17 \%$ of unique variance in reading scores, even when entered last into the equation $\left(\mathrm{R}_{\text {change }}^{2}=.166, \mathrm{~F}_{\text {change }}(1,155)=34.453, p<0.001\right)$. This suggests that 
although reaction time and speed of processing measures were related to RAN performance, they do not underlie the relationship between RAN and reading.

\section{General Discussion}

The current research aimed to shed light on some of the remaining questions concerning the processes that underlie performance on RAN tasks and which might be responsible for RAN's reliable relationship with reading. As a starting point, we assessed the performance of a large sample of typically developing seven to ten year-old British children attending mainstream schools on reading and reading-related skills. This enabled us to examine their profiles in the light of two theories which make different proposals with regard to the relationship between RAN and reading: the double deficit and the phonological core deficit hypothesis.

First, we investigated the degree to which our data were consistent with double deficit theory, (eg. Bowers \& Wolf, 1993; Wolf \& Bowers, 1999), which, as outlined earlier, regards the processes underlying RAN performance as at least partly independent of phonological processes. Our data were consistent with data reported by Wolf and Bowers: while the majority of children performed within the normal range on both RAN and phonological awareness, we also found amongst our sample children with a double deficit profile (deficits in both RAN and phonological awareness), some with a single phonological awareness deficit, and also a sample with a single RAN deficit. Both single RAN and single phonological awareness deficits were associated with modest deficits in reading, as assessed by a single word reading task. However, as predicted by double deficit theory, the least common profile was the double deficit profile, which was also associated with the most 
severe reading problems. Our data are thus broadly in keeping with double deficit theory, and extend the scope of the theory in accounting for the performance of a large sample of typically developing British children attending mainstream schools.

We next sought to investigate the degree to which our data were consistent with the phonological core deficit view of dyslexia. To do this, we first replicated a confirmatory factor analysis reported by Wagner et al. (1999) as part of the validation procedure for their Comprehensive Test of Phonological Processing. They described a model with 3 factors, phonological awareness, phonological memory and RAN, which provided a good fit to the data. There was a strong correlation between phonological awareness and phonological memory, both of which were moderately correlated with RAN. These findings were interpreted as consistent with the view that RAN tasks, like phonological awareness and phonological memory tasks, are an index of phonological processing. We applied the same model to our data, and obtained results (Model 1) that were strikingly similar to those reported by Wagner et al.. However, we were interested in investigating further the structure of the dataset by applying two alternative models to the data. First, we tested a two-factor model where phonological awareness and phonological memory were subsumed within one 'phonological processing' factor, and RAN formed a second factor. This model also provided a good fit to the data, and while its fit was less good than the original 3-factor solution, it may arguably provide a more parsimonious account of the data. A final confirmatory factor analysis was carried out, in which phonological awareness, phonological memory and RAN were all subsumed within a single latent 'phonological processing' variable. This single factor solution (Model 3), which is perhaps the strongest test of whether 
the processes underlying RAN can be considered as independent of phonological processing more generally, did not provide an adequate fit to the data.

We then used structural equation modeling to investigate the relationships between RAN, phonological memory and phonological awareness and reading, in such as way as to compare the models incorporating the three different measurement models described above. Specifically, reading was regressed on three latent variables (RAN, phonological memory and phonological awareness) in Model 4, on two latent variables (RAN and Phonological Processing) in Model 5, and on a single latent variable (Phonological Processing) in Model 6. Model 4, in which RAN, phonological memory and phonological awareness were instantiated as separate factors, provided the best fit to the data and obtained an $\mathrm{R}^{2}$ of .70. Model 5 provided a less good fit, though the two latent variables still accounted for a considerable amount of the variance in reading scores. Model 6, however, did not provide a good fit to the data. In our view, Model 6 provided the strongest test of the theoretical position, arising from the phonological core deficit account of dyslexia, which sees the processes underlying RAN and driving its relationship with reading as essentially phonological. The fact that this model did not provide a good fit to the data could thus be interpreted as providing evidence against this theory: not only does RAN predict unique variance in reading scores, but also while RAN is correlated with both phonological awareness and phonological memory, models in which RAN is subsumed within a phonological processing factor do not provide a good fit to our data.

As well as providing evidence of a dissociation between RAN and phonological awareness skills in our sample, we have also demonstrated through the structural equation modeling described above, that the processes underlying RAN performance may be at least in 
part independent of phonological processes, raising the question of which additional processes may be implicated.

We then investigated whether, as Kail (e.g., 1991) has suggested, individual differences in RAN are driven by individual differences in generalized speed of processing, by comparing a group of children slow on RAN with controls on their performance on speed of processing and reaction time tasks. The children in the low RAN group were slower than controls on both speed of processing and simple reaction time measures, providing some support for Kail's view that RAN is an index of processing speed. However, hierarchical regression analysis revealed that even when speed of processing and simple reaction time were entered first into the regression, RAN was still a significant predictor of reading, accounting for a unique $17 \%$ of the variance in reading scores. Thus although it appears that processing speed is a factor in RAN performance, it does not account for the relationship between RAN and reading. This is true even though our only measure of reading was a single word reading test. One possible limitation of the present study is that stronger effects might have been found had we also administered a measure of text reading fluency as performance on RAN has been consistently found to be related to fluency of text reading (Bowers, 1995; Morris, Stuebing, Fletcher, Shawitz, Lyon, Shankweiler et al., 1998; Pennington, Cardoso-Martins, Green \& Lefly, 2001).

To conclude, our results suggest that while phonological processes certainly play a part in RAN performance, processes independent of phonology also appear to be implicated. We have demonstrated that while generalized processing speed is associated with RAN performance, it cannot account for the relationship between RAN and reading, raising questions about which cognitive processes may be implicated in RAN. 
Theories agree that reading involves many different types of process, from the early uptake of visual information, to orthographic and semantic processes, to (in the case of reading aloud) the motor processes involved in articulation. As Wolf and Bowers (e.g., 1999) have pointed out, RAN tasks involve many of the same processes, and thus an understanding of which cognitive processes, aside from those related to phonology, drive performance on RAN tasks may offer a window on those non-phonological processes that can impact on reading development. If, as the data reported here suggest, there exists a subgroup of children whose reading problems are not caused solely by phonological deficits, then they will not be amenable to remediation through the now ubiquitous phonology-based reading interventions. A fuller understanding of the cognitive processes underlying RAN and accounting for its relationship with reading is thus of clear practical, as well as theoretical importance. We are currently engaged in a systematic investigation of the cognitive processes necessary to performance on RAN tasks, starting with the uptake of visual information, through lexical access, to the articulation of a spoken response. Many if not all of these processes are also necessary to word reading. The identification of selective deficits in one or more of these processes in the low RAN group relative to controls will help to elucidate the nature of the relationship between performance on RAN and word reading. 


\section{$\underline{\text { References }}$}

Ackerman, P. T., \& Dykman, R. A. (1993). Phonological processes, confrontation naming and immediate memory in dyslexia. Journal of Learning Disabilities, 26, 597-690.

Arbuckle, J. C. (2003). Amos 5.0.1 for Windows. Chicago: SmallWaters Corporation.

Badian, N. A. (1993). Phonemic awareness, naming, visual symbol processing, and reading. Reading and Writing: an Interdisciplinary Journal, 5, 87-100.

Badian, N. A. (1997). Dyslexia and the double deficit hypothesis. Annals of Dyslexia, 47, 69-87.

Bentler, P. M. (1988). Comparative fit indexes in structural models. Psychological Bulletin, 107, 238-246.

Bentler, P. M., \& Bonett, D. G. (1980). Significance tests and goodness of fit in the analysis of covariance structures. Psychological Bulletin, 88, 588-606.

Blachman, B. A. (1984). Relationship of rapid naming ability and language analysis skills to kindergarten and first-grade reading achievement. Journal of Educational Psychology, 76, 610-622.

Bollen, K. A. (1989). Structural equations with latent variables. New York: Wiley.

Bowers, P. G. (1995). Tracing symbol naming speed's unique contributions to reading disabilities over time. Reading and Writing: an Interdisciplinary Journal, 7, 189-216.

Bowers, P. G., Steffy, R., \& Tate, E. (1998). Comparison of the effects of IQ control methods on memory and naming speed predictors of reading disability. Reading Research Quarterly, 23, 304-309. 
Bowers, P. G., \& Wolf, M. (1993). Theoretical Links among Naming Speed, Precise Timing Mechanisms and Orthographic Skill in Dyslexia. Reading and Writing, 5(1), 69-85.

Brizzolara, D., Chilosi, A., \& Cipriani, P. (2006). Do phonologic and rapid automatized naming deficits differentially affect dyslexic children with and without a history of language delay? A study of Italian dyslexic children. Cognitive and Behavioral Neurology, 19(3), 141-149.

Compton, D.L., DeFries, J.C., \& Olson, R.K. (2001). Are RAN and phonological awareness deficits additive in children with reading disabilities? Dyslexia, 7, 125-149.

Cutting, L. E., \& Dencklan, M. B. (2001). The relationship of rapid serial naming and word reading in normally developing readers: an exploratory model. Reading and Writing, 14, 673-705.

Denckla, M. B., \& Rudel, R. G. (1974). Rapid 'automatized' naming of pictured objects, colors, letters and numbers by normal children. Cortex, 10, 186-202.

Denckla, M. B., \& Rudel, R. G. (1976). Rapid Automatized Naming (RAN) Dyslexia Differentiated from Other Learning-Disabilities. Neuropsychologia, 14(4), 471-479.

Elliot, C. D., Murray, D. J., \& Pearson, L. S. (1983). British Ability Scales. Windsor, UK: NFER-Nelson.

Felton, R. H., \& Brown, I. S. (1990). Phonological processes as predictors of specific reading skills in children at risk for reading failure. Reading and Writing: an Interdisciplinary Journal, 2, 39-59. 
Hulme, C., \& Snowling, M. J. (1992). Deficits in output phonology: An explanation of reading failure? Cognitive Neuropsychology, 9(47-72).

Kail, R. (1991). Development of Processing Speed in Childhood and Adolescence. Advances in Child Development and Behavior, 23, 151-185.

Kail, R., \& Hall, L. K. (1994). Processing Speed, Naming Speed, and Reading. Developmental Psychology, 30(6), 949-954.

Kail, R., Hall, L. K., \& Caskey, B. J. (1999). Processing speed, exposure to print, and naming speed. Applied Psycholinguistics, 20(2), 303-314.

Manis, F. R., Seidenberg, M. S., \& Doi, L. M. (1999). See Dick RAN: Rapid Naming and the Longitudinal Prediction of Reading Subskills in First and Second Graders. Scientific Studies of Reading, 3(2), 129-157.

McBride-Chang, C., \& Manis, F. R. (1996). Structural invariance in the associations of naming speed, phonological awareness, and verbal reasoning in good and poor readers: A test of the double deficit hypothesis. Reading and Writing: an Interdisciplinary Journal, 8, 323-339.

Morris, R., Stuebing, K., Fletcher, J., Shawitz, S., Lyon, R., Shankweiler, D., et al. (1998). Subtypes of reading disability: a phonological core. Journal of Educational Psychology, 90, 347-373.

Meyer, M.S., Wood, F. B., Hart, L. A., \& Felton, R. H. (1998). Selective predictive value of rapid automatized naming in poor readers. Journal of Learning Disabilities, 31(2), 106-117. 
Pennington, B. F., Cardoso-Martins, C., Green, P. A., Lefly, D. L. (2001).

Comparing the phonological and double deficit hypotheses for developmental dyslexia. Reading and Writing, 14, 707-755.

Schatschneider, C., Carlson, C. D., Francis, D. J., Foorman, B. R., \& Fletcher, J. M. (2002). Relationship of rapid automatized naming and phonological awareness in early reading development: Implications for the double-deficit hypothesis. Journal of Learning Disabilities, 35(3), 245-256.

Schneider, W., Eschman, A., \& Zuccolotto, A. (2002). E-Prime User's Guide. Pittsburgh: Psychology Software.

Share, D. L. (1995). Phonological recoding and self-teaching: Sine qua non of reading acquisition. Cognition, 55, 151-218.

Snowling, M. J. (2002). Dyslexia: Individual and developmental differences. In R. Stainthorp \& P. Tomlinson (Eds.), Learning and teaching reading. Monograph Series, British Journal of Educational Psychology. Leicester, UK: British Psychological Society.

Stainthorp, R., \& Tomlinson, P. (Eds.). (2002). Learning and Teaching Reading. Monograph Series, British Journal of Educational Psychology. Leicester: British Psychological Society.

Stanovich, K. E., \& Siegel, L. S. (1994). Phenotypic performance profile of children with reading disabilities - a regression-based test of the phonological-core variable-difference model. Journal of Educational Psychology, 86(24-53). 
Swanson, H. L., Trainin, G., Necoechea, D. M., \& Hammill, D. D. (2003). Rapid naming, phonological awareness, and reading: A meta-analysis of the correlation evidence. Review of Educational Research, 73(4), 407-440.

Torgesen, J. K., Wagner, R. K., Rashotte, C. A., Burgess, S., \& Hecht, S. (1997). Contributions of phonological awareness and rapid automatic naming ability to the growth of word-reading skills in second- to fifth-grade children. Scientific Studies of Reading, 1(2), 161-185.

Wagner, R. K., \& Torgesen, J. K. (1987). The nature of phonological processing and its causal role in the acquisition of reading skills. Psychological Bulletin, 101, 192-212.

Wagner, R. K., Torgesen, J. K., \& Rashotte, C. A. (1999). The Comprehensive Test of Phonological Processing. Texas: PRO-ED Inc.

Wagner, R. K., Torgesen, J. K., Rashotte, C. A., Hecht, S. A., Barker, T. A., Burgess, S. R., et al. (1997). Changing relations between phonological processing abilities and word-level reading as children develop from beginning to skilled readers: a 5-year longitudinal study. Developmental Psychology, 33(3), 468479.

Wimmer, H. (1993). Characterisitics of developmental dyslexia in a regular writing system. Applied Psycholinguistics, 14, 1-33.

Wolf, M. (1991). Naming speed and reading: The contribution of the cognitive neurosciences. Reading Research Quarterly, 26, 123-141.

Wolf, M., \& Bowers, P. G. (1999). The double-deficit hypothesis for the developmental dyslexias. Journal of Educational Psychology, 91(3), 415-438. 
Wolf, M., Bowers, P. G., \& Biddle, K. (2000). Naming-speed processes, timing, and reading: A conceptual review. Journal of Learning Disabilities, 33(4), 387407.

Woodcock, R. W., \& Johnson, M. B. (1989). Woodcock-Johnson Psycho-educational Battery-Revised. Chicago, IL: Riverside. 


\section{Author Note}

The research was supported by ESCR Grant No. RES-000-23-0699. We would like to thank the children and staff of the nine schools in the borough of Kingston Upon Thames, UK, who participated in the research. We also thank Lars-Erik Malmberg for advice on Structural Equation Modeling. 
Tables

Table 1

Mean (and standard deviation) scores for British Ability Scales single word reading (reading age and raw score) and for the six core subtasks of the Comprehensive Test of Phonological Processing (raw and standard scores) for the children in Year 3 and Year 4.

\begin{tabular}{lcc}
\hline & Year 3 & Year 4 \\
& $n=447$ & $n=437$ \\
& & \\
\hline BAS word reading (reading age in months) & 106.00 & 116.38 \\
& $(18.97)$ & $(21.29)$ \\
BAS word reading (raw score, of total 90 items) & 60.83 & 68.80 \\
& $(17.66)$ & $(15.32)$ \\
CTOPP Elision (raw score, of total 20 items) & 11.17 & 11.84 \\
& $(4.80)$ & $(4.94)$ \\
CTOPP Elision (standard score) & 10.45 & 9.63 \\
& $(2.96)$ & $(3.01)$ \\
CTOPP Blending (raw score, of total 20 items) & 9.21 & 9.21 \\
& $(2.90)$ & $(2.77)$ \\
CTOPP Blending (standard score) & 8.47 & 7.67 \\
& $(1.89)$ & $(1.69)$ \\
CTOPP Memory for digits (raw score, of total 21 items) & 12.25 & 12.81 \\
& $(2.53)$ & $(2.86)$ \\
CTOPP Memory for digits (standard score) & 9.92 & 9.82 \\
& $(2.54)$ & $(2.84)$ \\
CTOPP Non-word repetition (raw score, of total 18 items) & 7.49 & 7.87 \\
& $(2.26)$ & $(2.43)$ \\
CTOPP Non-word repetition (standard score) & 7.81 & 7.65 \\
& $(1.72)$ & $(1.85)$ \\
CTOPP RAN Letters (raw score, in seconds) & 44.67 & 39.09 \\
& $(12.10)$ & $(8.84)$ \\
CTOPP RAN Letters (standard score) & 10.78 & 10.69 \\
& $(2.11)$ & $(2.10)$ \\
CTOPP RAN Digits (raw score, in seconds) & 40.32 & 36.37 \\
& $(9.36)$ & $(7.85)$ \\
CTOPP RAN Digits (standard score) & 10.89 & 10.63 \\
& $(2.05)$ & $(2.11)$ \\
\hline
\end{tabular}

Note. BAS $=$ British Ability Scales CTOPP $=$ Comprehensive Test of Phonological Processing. 
Table 2

Mean (and standard deviation) z-scores for phonological awareness, RAN and British Ability Scales word reading for year 3 and Year 4 children falling into each of the four deficit subgroups. Number of children, and percentage per year group, falling into each subgroup is also shown.

\begin{tabular}{|c|c|c|c|c|}
\hline & & PA (z) & $\mathbf{R A N}(\mathbf{z})$ & BAS (z) \\
\hline \multirow[t]{4}{*}{ Year 3} & $\begin{array}{l}\text { No Deficit } \\
N=323,74 \%\end{array}$ & $.32(.86)$ & $.32(.64)$ & $.32(.75)$ \\
\hline & $\begin{array}{l}\text { Single PA Deficit } \\
\mathrm{N}=51,12 \%\end{array}$ & $-1.26(.24)$ & $.04(.53)$ & $-.82(.88)$ \\
\hline & $\begin{array}{l}\text { Single RAN Deficit } \\
\mathrm{N}=37,9 \%\end{array}$ & $-.03(.77)$ & $-1.71(.77)$ & $-.49(1.07)$ \\
\hline & $\begin{array}{l}\text { Double Deficit } \\
N=25,6 \%\end{array}$ & $-1.43(.41)$ & $-2.07(1.07)$ & $-1.57(1.15)$ \\
\hline \multirow[t]{4}{*}{ Year 4} & $\begin{array}{l}\text { No Deficit } \\
\mathrm{N}=317,73 \%\end{array}$ & $.32(.83)$ & $.29(.66)$ & $.29(.70)$ \\
\hline & $\begin{array}{l}\text { Single PA Deficit } \\
\mathrm{N}=55,13 \%\end{array}$ & $-1.34(.21)$ & $.06(.61)$ & $-.65(1.19)$ \\
\hline & $\begin{array}{l}\text { Single RAN Deficit } \\
\mathrm{N}=44,10 \%\end{array}$ & $-.13(.76)$ & $-1.83(1.01)$ & $-.62(1.18)$ \\
\hline & $\begin{array}{l}\text { Double Deficit } \\
N=20,5 \%\end{array}$ & $-1.53(.39)$ & $-1.64(.48)$ & $-1.48(1.45)$ \\
\hline
\end{tabular}

Note: $\mathrm{BAS}=$ British Ability Scales word reading, $\mathrm{PA}=$ phonological awareness 
Table 3

Correlations between raw scores for the British Ability Scales word reading test, and for the Comprehensive Test of Phonological Processing measures of elision, blending, memory for digits, nonword repetition, RAN letters and RAN digits.

\begin{tabular}{|c|c|c|c|c|c|c|c|}
\hline Task & 1 & 2 & 3 & 4 & 5 & 6 & 7 \\
\hline 1. Word reading & - & $.57 * * *$ & $.37 * * *$ & $.36^{* * *}$ & $.30 * * *$ & $-.53 * * *$ & $-.53 * * *$ \\
\hline 2. Elision & & - & $.31 * * *$ & $.30 * * *$ & $.18 * * *$ & $-.29 * * *$ & $-.31 * * *$ \\
\hline 3. Blending & & & - & $.263 * * *$ & $.31 * * *$ & $-.19 * * *$ & $-.19 * * *$ \\
\hline 4. Memory for Digits & & & & - & $.36 * * *$ & $-.16 * * *$ & $-.24 * * *$ \\
\hline 5. Nonword repetition & & & & & - & $-.17 * * *$ & $-.17 * * *$ \\
\hline 6. RAN letters & & & & & & - & $.77 * * *$ \\
\hline 7. RAN digits & & & & & & & - \\
\hline
\end{tabular}

Note. $* * *=p<0.001$ 
Table 4

Comparative goodness of fit of the three Confirmatory Factor Analysis Models run on the data from the six core subtests of the CTOPP.

\begin{tabular}{|c|c|c|c|c|c|c|c|c|c|c|c|}
\hline \multirow[b]{2}{*}{ Model } & \multicolumn{3}{|c|}{ Model fit } & \multicolumn{3}{|c|}{$\begin{array}{l}\text { Goodness } \\
\text { of Fit }\end{array}$} & \multicolumn{2}{|c|}{ Test of Closeness } & \multicolumn{3}{|c|}{$\begin{array}{l}\text { Step-down } \\
\text { Goodness of Fit }\end{array}$} \\
\hline & df & $X^{2}$ & $p<$ & NFI & IFI & CFI & RMSEA & $\begin{array}{l}90 \% \\
\text { CI }\end{array}$ & df & $X^{2}$ & $p<$ \\
\hline $\begin{array}{l}\text { 1: } 3 \text { factor } \\
\text { solution }\end{array}$ & 6 & 37.531 & 0.001 & .971 & .976 & .975 & .077 & $\begin{array}{l}.055- \\
.102\end{array}$ & & & \\
\hline $\begin{array}{l}\text { 2: } 2 \text { factor } \\
\text { solution }\end{array}$ & 8 & 56.912 & 0.001 & .956 & .962 & .962 & .083 & $\begin{array}{l}.064- \\
.104\end{array}$ & 2 & 19.381 & 0.001 \\
\hline $\begin{array}{l}\text { 3: } 1 \text { factor } \\
\text { solution }\end{array}$ & 9 & 279.766 & 0.001 & .785 & .790 & .788 & .185 & $\begin{array}{l}.166- \\
.204\end{array}$ & 1 & 222.854 & 0.001 \\
\hline
\end{tabular}

Note. $\mathrm{df}=$ degrees of freedom; NFI $=$ Normed Fit Index; IFI = Incremental Fit Index; CRI = Comparative Fit Index; RMSEA = Root Mean Square Error of Approximation; $\mathrm{CI}=$ confidence interval. 
Table 5

Comparative goodness of fit of the three Structural Equation Models run on the data from the six core subtests of the Comprehensive Test of Phonological Processing and the British Ability Scales single word reading test.

\begin{tabular}{|c|c|c|c|c|c|c|c|c|c|c|c|}
\hline \multirow[b]{2}{*}{ Model } & \multicolumn{3}{|c|}{ Model fit } & \multicolumn{3}{|c|}{$\begin{array}{l}\text { Goodness } \\
\text { of Fit }\end{array}$} & \multicolumn{2}{|c|}{ Test of Closeness } & \multicolumn{3}{|c|}{$\begin{array}{l}\text { Step-down } \\
\text { Goodness of Fit }\end{array}$} \\
\hline & df & $X^{2}$ & $p<$ & NFI & IFI & CFI & RMSEA & $\begin{array}{l}90 \% \\
\text { CI }\end{array}$ & df & $X^{2}$ & $p<$ \\
\hline $\begin{array}{l}3 \text { factor } \\
\text { solution }\end{array}$ & 9 & 47.726 & 0.001 & .975 & .980 & .979 & .070 & $\begin{array}{l}.051- \\
.090\end{array}$ & & & \\
\hline $\begin{array}{l}2 \text { factor } \\
\text { solution }\end{array}$ & 12 & 90.613 & 0.001 & .953 & .959 & .958 & .086 & $\begin{array}{l}.070- \\
.103\end{array}$ & 3 & 42.887 & 0.001 \\
\hline $\begin{array}{l}1 \text { factor } \\
\text { solution }\end{array}$ & 14 & 532.351 & 0.001 & .722 & .727 & .725 & .205 & $\begin{array}{l}.190- \\
.220\end{array}$ & 2 & 441.738 & 0.001 \\
\hline
\end{tabular}

Note. df $=$ degrees of freedom; NFI = Normed Fit Index; IFI = Incremental Fit Index; CRI = Comparative Fit Index; RMSEA = Root Mean Square Error of Approximation; $\mathrm{CI}=$ confidence interval. 
Table 6

Mean (and standard deviation) raw scores on Phonological Awareness (PA), Phonological Memory (PM) and RAN core subtests of the Comprehensive Test of Phonological Processing, chronological age, and scaled scores on the Block Design and Vocabulary subtests of the WISC IIIR for Low RAN and Controls in Years 3 and 4.

\begin{tabular}{lcccc}
\hline & \multicolumn{2}{c}{ Year 3 } & \multicolumn{2}{c}{ Year 4 } \\
\hline & $\begin{array}{c}\text { Low RAN } \\
(\mathrm{n}=37)\end{array}$ & $\begin{array}{c}\text { Controls } \\
(\mathrm{n}=37)\end{array}$ & $\begin{array}{c}\text { Low RAN } \\
(\mathrm{n}=43)\end{array}$ & $\begin{array}{c}\text { Controls } \\
(\mathrm{n}=43)\end{array}$ \\
\hline PA (raw score) & 20.35 & 20.38 & 20.49 & 19.93 \\
& $(4.84)$ & $(5.20)$ & $(4.85)$ & $(4.45)$ \\
PM (raw score) & 18.97 & 18.86 & 20.51 & 20.14 \\
& $(3.73)$ & $(2.66)$ & $(3.53)$ & $(2.88)$ \\
RAN (raw score in ms) & 117.69 & 78.54 & 103.44 & 70.74 \\
& $(14.99)$ & $(12.80)$ & $(16.03)$ & $(10.14)$ \\
Age (months) & 92.24 & 93.00 & 105.09 & 105.60 \\
& $(3.04)$ & $(3.51)$ & $(4.08)$ & $(3.67)$ \\
WISC IIIR Block & 8.84 & 8.76 & 8.93 & 8.40 \\
Design (scaled score) & $(4.22)$ & $(3.95)$ & $(4.02)$ & $(3.49)$ \\
WISC IIIR Vocabulary & 11.14 & 10.86 & 10.56 & 9.98 \\
(scaled score) & $(3.44)$ & $(3.17)$ & $(3.47)$ & $(3.04)$ \\
\hline
\end{tabular}


Table 7

Mean (and sd) scores on the speed of processing cross-out task, the simple reaction time task and the choice reaction time task for Low Ran and Control groups in both Year 3 and Year 4.

\begin{tabular}{lcccc}
\hline & \multicolumn{2}{c}{ Year 3 } & \multicolumn{2}{c}{ Year 4 } \\
\hline & Low RAN & Control & Low RAN & Control \\
\hline SoP (No. correct/30) & $14.30(3.05)$ & $15.08(2.62)$ & $15.93(3.38)$ & $17.19(3.28)$ \\
SRT (ms) & $369(77)$ & $341(59)$ & $337(59)$ & $324(62)$ \\
CRT (ms) & $573(103)$ & $569(91)$ & $561(87)$ & $514(93)$ \\
\hline
\end{tabular}

Note: $\mathrm{SoP}=$ speed of processing cross-out task; $\mathrm{SRT}=$ simple reaction time task; $\mathrm{CRT}=$ choice reaction time task . 
Table 8

Correlations between reading, RAN, speed of processing and Simple Reaction time measures.

\begin{tabular}{llllll}
\hline Task & $\mathbf{1}$ & $\mathbf{2}$ & $\mathbf{3}$ & $\mathbf{4}$ & $\mathbf{5}$ \\
\hline 1. BAS single word reading & - & $.48 * * *$ & $.29 * * *$ & .13 & $.17 *$ \\
2. RAN & - & $.27 * * *$ & $.24 * *$ & $.22 * *$ \\
3. Speed of Processing & & - & $.19 *$ & $.44 * * *$ \\
4. Simple Reaction Time & & & - & $.44 * * *$ \\
5. Choice Reaction Time & & & & - \\
\hline
\end{tabular}

Note. $*=p<0.05 ; * *=p<0.01 ; * * *=p<0.001$; BAS = British Ability Scales. 


\section{Figure Captions}

Figure 1. Relationship between RAN and phonological awareness (PA) in children in Year 3 (left panel) and Year 4 (right panel). Vertical bar indicates cut-off point of one sd below mean in RAN performance; horizontal bar indicates one sd below mean in PA.

Figure 2. Model 1: Three factor model of children's scores on the six core subtests of the Comprehensive Test of Phonological Processing. Correlations between the three constructs (Phonological Awareness, Phonological Memory, RAN) are represented by double headed arrows, and factor loadings are shown with single-headed arrows. Squared multiple correlations for each of the observed variables are given on the far right of the figure.

Figure 3. Model 2: Two factor model of children's scores on the six core subtests of the Comprehensive Test of Phonological Processing. Correlations between the factors are represented by double headed arrows, and factor loadings are shown with single-headed arrows. Squared multiple correlations for each of the observed variables are given on the far right of the figure.

Figure 4. Model 3: Single factor model of children's scores on the six core subtests of the Comprehensive Test of Phonological Processing. Factor loadings are shown with single-headed arrows. Squared multiple correlations for each of the observed variables are given on the far right of the figure.

Figure 5. Model 4: Structural equation model estimating the relationships between three constructs (Phonological Awareness, Phonological Memory, and RAN) and reading (British Ability Scales single word reading scores). Correlations between the factors are represented by double headed arrows, and factor loadings are shown with single-headed arrows. Squared multiple correlations for each of the observed variables are given on the far right of the figure.

Figure 6. Model 5: Structural equation model estimating the relationships between two constructs (Phonological Processing and RAN) and reading (British Ability Scales single word reading scores). Correlations between the factors are represented by double headed arrows, and factor loadings are shown with single-headed arrows. Squared multiple correlations for each of the observed variables are given on the far right of the figure.

Figure 7. Model 6: Structural equation model estimating the relationship between a single construct (Phonological Processing) and reading (British Ability Scales single word reading scores). Factor loadings are shown with single-headed arrows. Squared multiple correlations for each of the observed variables are given on the far right of the figure. 
Figure 1

Year 3

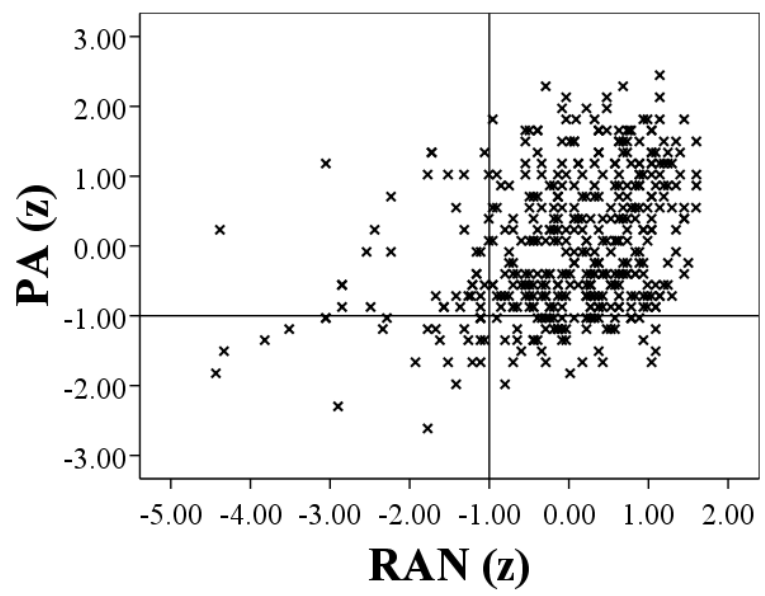

Year 4

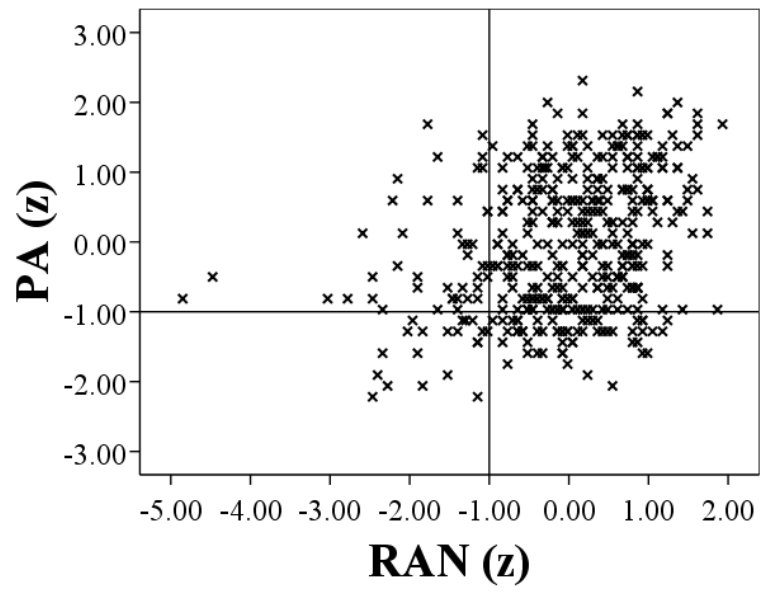


Figure 2

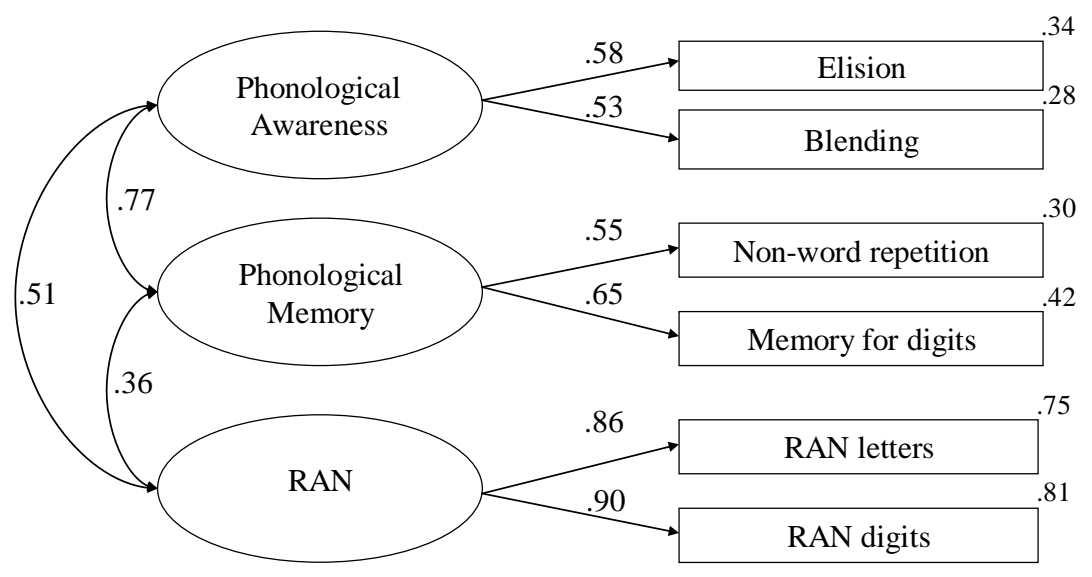


Figure 3

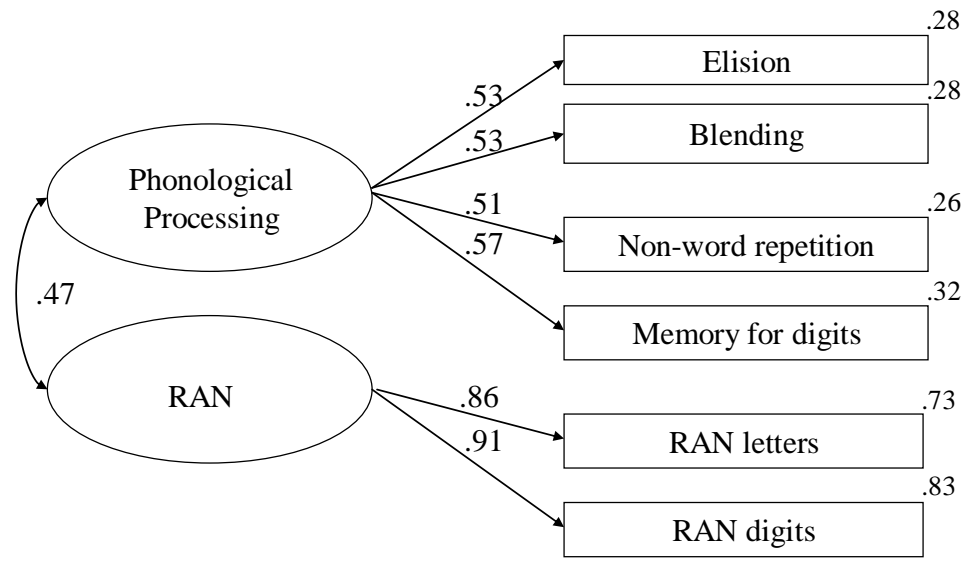


Figure 4

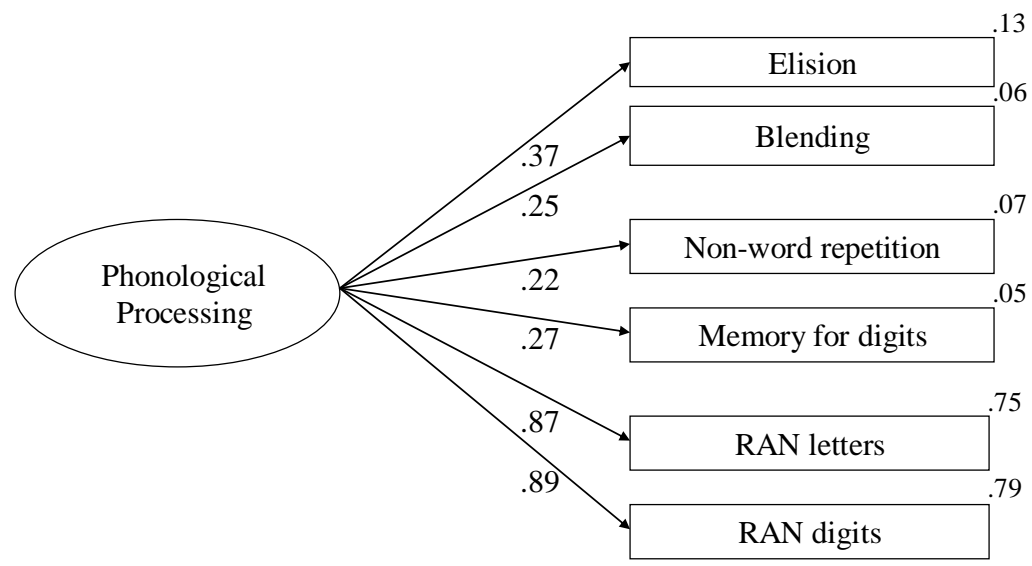


Figure 5

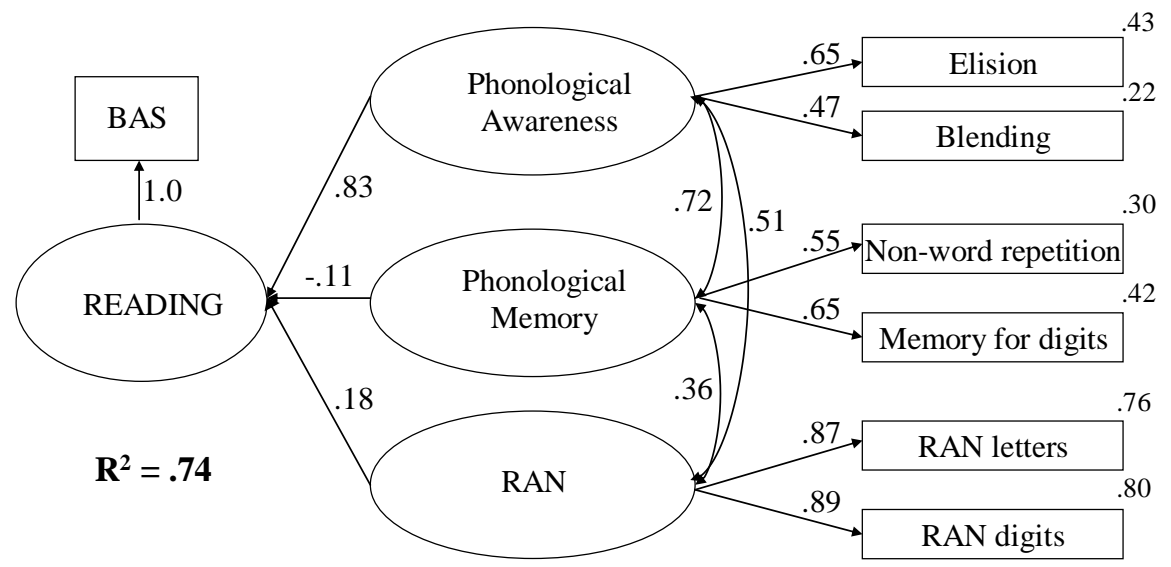


Figure 6

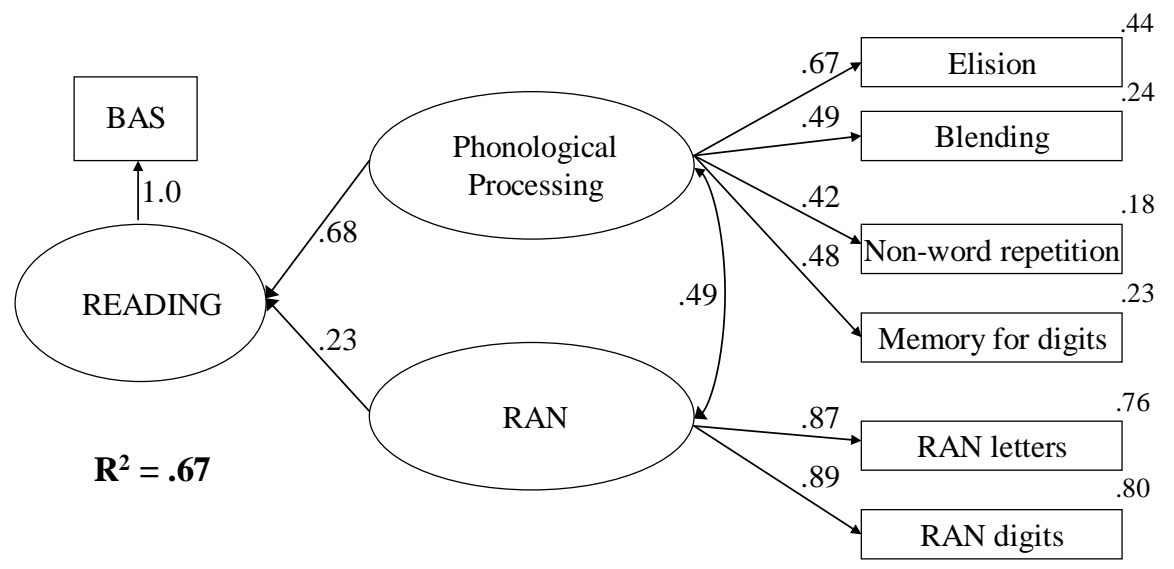


Figure 7

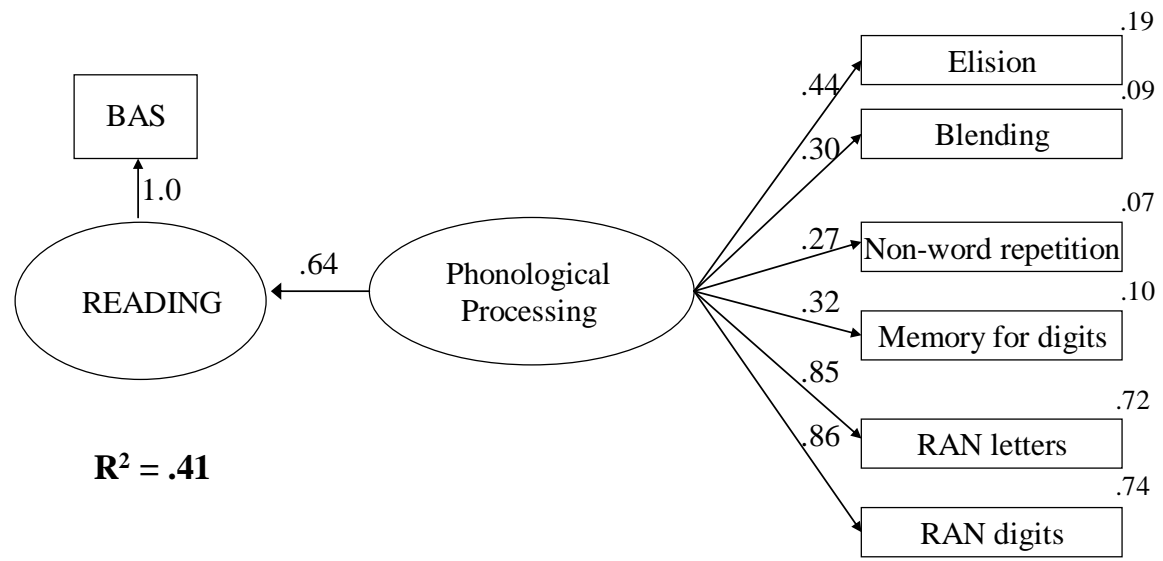

